\title{
TRABALHO DE CAMPO - NOTAS PARA INICIANTES EM ANTROPOLOGIA
}

\author{
TRABAJO DE CAMPO - NOTAS PARA PRINCIPIANTES EN ANTROPOLOGÍA \\ FIELDWORK - NOTES FOR BEGINNERS IN ANTHROPOLOGY
}

Vítor Lopes ANDRADE ${ }^{1}$

RESUMO: O objetivo deste artigo é trazer ao leitor/a algumas discussões que foram feitas na disciplina Trabalho de Campo, Ética, Subjetividade e Engajamento, ministrada pela professora doutora Miriam Pillar Grossi. As aulas aconteceram no curso de graduação em Antropologia da Universidade Federal de Santa Catarina (UFSC) durante o segundo semestre do ano letivo de 2014. O objetivo aqui é compartilhar algumas importantes questões acerca de trabalho de campo com outros iniciantes na Antropologia. Desse modo, abordar-se-á a relação entre trabalho de campo e Antropologia, o uso do diário etnográfico e a realização de entrevistas, bem como reflexões acerca da escrita antropológica.

PALAVRAS-CHAVE: Diário de campo. Entrevista. Anonimato. Antropólogo iniciante.

RESUMEN: El propósito de este artículo es llevar al lector algunas discusiones que se realizaron en el trabajo de campo, ética, subjetividad y compromiso, impartido por la profesora Miriam Pillar Grossi. Las clases se llevaron a cabo en el Curso de Antropología de la Universidad Federal de Santa Catarina (UFSC) durante el segundo semestre del año escolar 2014. El objetivo aquí es compartir algunas preguntas importantes sobre el trabajo de campo con otros principiantes en Antropología. Así, se abordará la relación entre el trabajo de campo y la antropología, el uso del diario etnográfico y las entrevistas, así como las reflexiones sobre la escritura antropológica.

PALABRAS CLAVE: Diario de campo. Entrevista. Anonimato. Antropólogo principiante.

ABSTRACT: The purpose of this article is to bring to the reader some discussions that were made in the Fieldwork, Ethics, Subjectivity and Engagement discipline, taught by Professor Miriam Pillar Grossi. The classes were held at the Anthropology Undergraduate Course at the Federal University of Santa Catarina (UFSC) during the second semester of the 2014 school year. The goal here is to share some important questions about fieldwork with other beginners in Anthropology. Thus, the relationship between fieldwork and anthropology, the use of ethnographic diary and interviews, as well as reflections on anthropological writing will be addressed.

KEYWORDS: Field diary. Interview. Anonymity. Beginner anthropologist.

${ }^{1}$ School of Global Studies da University of Sussex, Falmer - Inglaterra. Doutorando em Antropologia Social. ORCID: https://orcid.org/0000-0003-2750-0876. E-mail: vitorlandrade@yahoo.com.br 


\section{Introdução}

Este artigo traz algumas discussões que foram realizadas ao longo do segundo semestre letivo de 2014 na disciplina optativa Trabalho de Campo, Ética, Subjetividade e Engajamento. Essa matéria foi ofertada no curso de graduação em Antropologia da Universidade Federal de Santa Catarina (UFSC) pela professora doutora Miriam Pillar Grossi e sua estagiária-docente Anahí Guedes de Mello (doutoranda em Antropologia Social). As notas aqui contidas são, portanto, fruto das décadas de conhecimento antropológico que a doutora Miriam Grossi adquiriu, bem como das contribuições/reflexões que foram feitas em sala de aula por sua estagiária-docente e pelos meus dezenove colegas que também frequentaram a disciplina. Salienta-se, entretanto, que esse texto é a minha percepção acerca dos temas que foram debatidos nas aulas.

Duas questões fizeram com que a turma dessa disciplina fosse diferente do que normalmente se encontra em uma classe do curso de Antropologia. A primeira é que a nossa estagiária-docente é surda oralizada, o que se mostrou como uma experiência fantástica para nós, já que nos exigiu atenção com questões simples, que passariam despercebidas não fosse a presença da Anahí em sala de aula: não falar com a mão na boca e olhar para ela quando estávamos nos manifestando, por exemplo, uma vez que ela faz leitura labial. Foi um aprendizado de como lidar com a diferença (ponto central da Antropologia) na prática, na sala de aula. A segunda questão é que por ser uma matéria optativa, os/as alunos/as eram de diferentes fases das graduações em Antropologia e Ciências Sociais. Ainda mais interessante era o fato de que vários/as já haviam iniciado diferentes cursos antes de chegarem à Antropologia, como Filosofia e Cinema. Duas alunas eram formadas em Psicologia. É nesse contexto interdisciplinar que preciso me colocar, a fim de que se entenda o objetivo deste artigo.

Graduado em Relações Internacionais, decidi por cursar a pós-graduação em Antropologia Social: foi assim que começou a minha liminaridade ${ }^{2}$. Comecei a frequentar disciplinas da graduação e da pós-graduação em Antropologia da UFSC a fim de me preparar para o processo seletivo do mestrado. Mas, nesse processo, sou lembrado, o tempo todo, de que não tenho formação na área. Ou seja, não tenho 'pedigree’. Essa categoria - 'antropólogo/a pedigree' - me foi dita em uma mesa de bar, após o encerramento de uma disciplina da pós-

${ }^{2} \mathrm{O}$ conceito de liminaridade foi cunhado pelo antropólogo britânico Victor Turner e se refere a um estado de marginalidade, no qual não se é mais o que se era antes e ainda não se é o que vai ser depois, como, por exemplo, em ritos de passagem entre meninos em grupos africanos. Durante esses ritos, normalmente os rapazes são afastados das demais pessoas de seu grupo; é comum que haja momentos de sofrimento e dor; esse período marca o deslocamento da infância para a idade adulta. Ver Turner (2005). 
graduação (esse bar é muito frequentado por universitários/as, por se localizar bem próximo à UFSC. É comum que os/as alunos/as e professores/as se reúnam por lá após o encerramento de eventos e disciplinas). Ao serem indagado por mim sobre a sua formação, ele que está no doutorado em Antropologia Social, respondeu pomposamente: "graduação em Antropologia, mestrado em Antropologia e agora doutorado em Antropologia. Eu tenho 'pedigree'!".

Em outros momentos, não só na mesa do bar, fui lembrado de que não tenho o tal do 'pedigree' (professores/as gostam, muitas vezes, de salientar esse ponto. Um colega, já no mestrado, também ficou surpreso, na fila do Restaurante Universitário, quando descobriu que não sou das Sociais). Mas o que é 'pedigree”? "É um certificado de animais de raça pura [...] Os pedigrees revelam informação detalhada sobre a linha ancestral do animal, ou seja, sobre a

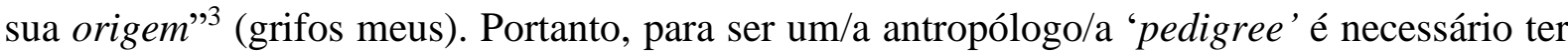
graduação em Antropologia ou em Ciências Sociais. Daí decorrem duas questões importantes.

A primeira é que muitos/as dos/as antropólogos/as mais renomados não tiveram formação acadêmica inicial na área. Franz Boas e Claude Lévi-Strauss, por exemplo - maiores representantes do Culturalismo e do Estruturalismo, duas teorias clássicas da Antropologia vinham de outros campos do conhecimento. Mas, é verdade, naquela época a Antropologia ainda estava sendo fundada. Podemos, então, indicar um exemplo mais recente: Manuela Carneiro da Cunha, antropóloga luso-brasileira, ex-presidente da ABA (Associação Brasileira de Antropologia) e que é muito reconhecida pelos seus trabalhos, teve formação inicial em Matemática. $^{4}$

Podemos também recorrer a exemplos mais próximos: cerca de nove dos/as docentes do Programa de Pós-graduação em Antropologia Social da UFSC não têm formação original em Ciências Sociais, mas sim em História, Filosofia, Comunicação Social, Engenharia, Música, Publicidade e Propaganda, e Arquitetura e Urbanismo. Sílvio Coelho dos Santos, nome fundamental no que diz respeito à Antropologia na UFSC e em relação à etnologia indígena no sul do Brasil, era formado em História, tendo, somente após a graduação, realizado uma especialização em Antropologia no Museu Nacional/RJ. O que isso significa? É preciso relativizar essa questão da formação inicial em Antropologia: excelentes antropólogos/as não tiveram graduação na área, assim como o fato de ter uma graduação neste campo não é sinônimo de sucesso acadêmico garantido.

A segunda questão é que preciso expor esse contexto para que se entenda o meu local de fala. De acordo com a feminista Donna Haraway (1995), a objetividade não significa o

\footnotetext{
${ }^{3}$ Definição disponível em: http://www.significados.com.br/pedigree/. Acesso em: 18 nov. 2014.
}

${ }^{4}$ Clifford Geertz e Roy Wagner também só chegaram à Antropologia na pós-graduação. 
distanciamento positivista entre o/a pesquisador/a e seu objeto de estudo - que pressupunha uma 'neutralidade' científica -, mas sim a localização dos saberes, isto é, o conhecimento situado e corporificado:

[...] a objetividade revela-se como algo que diz respeito à corporificação específica e particular e não definitivamente, como algo a respeito da falsa visão que promete transcendência de todos os limites e responsabilidades. A moral é simples: apenas a perspectiva parcial promete visão objetiva (HARAWAY, 1995, p. 21).

Desse modo, percebe-se que a produção de conhecimento não é neutra. É preciso assumir o local de onde se fala, se escreve. O meu local, no momento, é esse: a liminaridade de quem vem de outra área do conhecimento, mas pretende se tornar um antropólogo. É, pois, pensando nesse meu contexto que resolvi fazer como trabalho final da disciplina supracitada um artigo com algumas notas para iniciantes em Antropologia, tendo em mente, especificamente, os/as sujeitos/as que vêm de outros campos do saber nos quais as discussões sobre trabalho de campo são diferentes ou mesmo inexistentes. Ou seja, escrevo para possíveis antropólogos/as que, como eu, também não possuem 'pedigree'.

\section{Trabalho de Campo}

Ao mencionar trabalho de campo na Antropologia, imediatamente se pensa em Bronislaw Malinowski, o antropólogo polonês radicado no Reino Unido. Malinowski não foi o criador deste método, isto é, não foi o primeiro a realizá-lo: antes dele Boas, Rivers e até mesmo Morgan já haviam feito incursões a campo. Entretanto, foi Malinowski quem primeiro sistematizou como o/a antropólogo/a deveria se colocar em campo, criando a 'observação participante', apresentada na famosa introdução de sua obra Argonautas do Pacífico Ocidental (1922). A fim de se conhecer de maneira aprofundada um grupo - como os trobriandeses, no caso de Malinowski - seria necessário passar um grande período vivendo entre eles/as, afastado de outros 'brancos'. Era essencial que se conseguisse o maior número possível de informações acerca da organização social do grupo, mas que também se verificasse como as relações sociais se davam, de fato, na prática (pode haver diferença entre as regras sociais e a forma como as pessoas vivem, seguindo ou não essas regras). O/a antropólogo/a deveria observar os 'imponderáveis da vida real', ou seja, a forma como se preparam os alimentos, as amizades e inimizades que os/as nativos/as tinham, etc. Para tanto, Malinowski afirma ser necessário o uso de diário de campo, ou diário etnográfico. De fato, até hoje o uso do diário continua sendo 
imprescindível ao trabalho de campo e por isso voltaremos a esse ponto no decorrer do texto. Outro item salientado por Malinowski é que o/a antropólogo/a deveria, ele/a mesmo/a, aprender a língua nativa, a fim de não ficar na dependência de intérpretes e, dessa forma, conseguir atingir a mentalidade dos/as nativos/as, isto é, a forma como eles/as pensam.

É evidente que muito se modificou na maneira de fazer trabalho de campo desde que Malinowski esteve entre os trobriandeses. Naquela época, a Antropologia ainda estava restrita à pesquisa em grupos longínquos, exóticos e supostamente isolados, como os povos melanésios. Entretanto, ainda nos dias atuais, muitas das proposições de Malinowski fazem sentido, como a importância do diário de campo, por exemplo. $\mathrm{O}$ fato de se aprender a língua nativa também: não necessariamente um idioma estrangeiro, mas, por exemplo, no caso de se estudar algum segmento de sua própria sociedade, o/a antropólogo/a deve aprender a forma de comunicação entre os membros daquele grupo, os jargões, gírias, etc., conforme coloca Gilberto Velho (1978).

No artigo A situação etnográfica: andar e ver, Hélio Silva (2009) afirma que o trabalho de campo se constitui de três fases sincrônicas: a circulação no campo (situar-se/andar), a observação no campo (ver) e a versão do/a antropólogo/a do que aconteceu em campo (escrever). A fim de se situar entre os/as seus/suas interlocutores/as, o/a antropólogo/a deve buscar sua localização em campo, localização pensada em sua relação com os atores sociais que observa. E é através do 'andar' pelo espaço no qual a pesquisa se realiza que o/a antropólogo/a se situa, ou seja, adquire naquele contexto um lugar e uma identidade. É um percurso marcado pela interação: “essa interação implica mutualidade. Nessa ação, o etnógrafo sofre e exerce influência dos/sobre os outros, afeta e é afetado" (SILVA, 2009, p. 179). A característica da interação também se apresenta na observação que se faz em campo (o 'ver'): "estamos a observar idiossincraticamente uma cena da qual fazemos parte. O que envolve, além da relatividade que a subjetividade impõe à percepção, a capacidade de se incluir como peça exterior cuja presença altera a cena" (SILVA, 2009, p. 179-180). É devido a essa marca interacional que Hélio Silva define a etnografia como um 'relato' de uma 'experiência conflituosa' de um 'observador' (SILVA, 2009, p. 187).

Antes de nos concentrarmos sobre o 'escrever' na Antropologia, alguns comentários acerca do situar-se/andar/observar são necessários. O primeiro ponto: se é necessário 'andar' e 'ver' para fazer trabalho de campo, pessoas que não andam ou que são cegas não podem ser antropólogos/as $?^{5}$

${ }^{5}$ Talvez essa discussão não tivesse surgido durante as aulas se a nossa estagiária-docente não fosse surda oralizada. 
A fim de responder à pergunta acima, basta recorrermos a alguns exemplos. O primeiro se refere à grega Margarita Xanthakou e ao brasileiro José Augusto Laranjeira Sampaio, mais conhecido como Guga, ambos antropólogos/as e cegos/as. O outro exemplo se trata do clássico livro "O crisântemo e a espada" da antropóloga norte-americana Ruth Benedict (1972). Nesta obra, a autora compara as personalidades estadunidense e japonesa, mas sem realizar trabalho de campo no Japão, isto é, ela não esteve na Ásia. Foi através de filmes e livros de literatura, por exemplo, que Benedict analisou em que aspectos a personalidade japonesa diferia da estadunidense. Essa metodologia 'alternativa', ou seja, uma pesquisa em que não houve deslocamento geográfico e no qual não foi preciso 'andar' nos leva a um segundo ponto: a Antropologia necessita, obrigatoriamente, de trabalho de campo?

É justamente a associação privilegiada que se costuma fazer entre trabalho de campo e Antropologia que Emerson Giumbelli problematiza em seu artigo "Para além do "trabalho de campo': reflexões supostamente malinowskianas" (2002). O autor afirma que muita coisa mudou na Antropologia desde os tempos de Malinowski (conforme expusemos acima), mas que a opinião de que o trabalho de campo seja o método privilegiado na área ainda parece hegemônica (GIUMBELLI, 2002, p. 92). Partindo de suas próprias experiências de pesquisa no mestrado e no doutorado, nas quais não realizou trabalho de campo, o autor afirma não restar dúvida de que existem outras metodologias para se fazer Antropologia: "o volume e a variedade de pesquisas conduzidas no âmbito de espaços e instituições referidos à antropologia que se utilizam de fontes (às vezes exclusivamente) históricas e de técnicas distintas da observação participante não deixam margens à dúvida" (GIUMBELLI, 2002, p. 92). Portanto, apesar de não ser o único método possível de fazer pesquisa antropológica, o trabalho de campo é a forma hegemônica ${ }^{6}$ e os/as iniciantes na área, sem 'pedigree', devem ter conhecimentos sólidos acerca dessa metodologia.

Duas técnicas são usadas recorrentemente quando se está em campo: o diário etnográfico e a realização de entrevistas.

O diário é imprescindível para o trabalho de campo:

[...] é o primeiro suporte da elaboração teórica de uma pesquisa. Mas tem a virtude de preservar visível o processo todo de elaboração dela. Isso pode ser secundário em outro tipo de ciência; é fundamental em uma ciência reflexiva como [a Antropologia] (CALAVIA SÁEZ, 2013, p. 167).

6 “Para muitos, o 'trabalho de campo' consiste em um ritual de passagem obrigatório na formação de um antropólogo" (GIUMBELLI, 2002, p. 92). 
Deve ser escrito todos os dias, antes de se dormir, a fim de que não se esqueça de nenhum detalhe importante (caso se deixe para escrever no dia seguinte, por exemplo, alguns pontos podem ser esquecidos):

O primeiro método de trabalho consistirá em iniciar um diário de viagem onde se anotará, todas as noites, o trabalho realizado durante o dia; fichas preenchidas e objetos recolhidos entrarão neste diário que consistirá em um repertório fácil de consultar (MAUSS, 1993, p. 30).

O diário não é o mesmo que o bloco de notas. Este deve ser pequeno para que o/a antropólogo/a o leve sempre consigo ${ }^{7}$. Nele são escritos os pontos mais importantes, as palavras-chaves, no momento mesmo em que se está em campo. No bloco de notas se escreve o que se está escutando, o que se vê, ou seja, o que está acontecendo. Primeiro se anotam, portanto, os pontos mais relevantes no bloco de notas. Posteriormente, após ter retornado do campo, deve-se escrever o diário sobre aquele dia.

O diário é escrito de maneira discursiva, isto é, não são somente os tópicos mais importantes, como no bloco de notas. Deve ser dividido em duas partes: o lado esquerdo e o lado direito. Na esquerda, colocam-se as questões subjetivas, aquilo que não se quer tornar público, a forma como se sentiu em campo, como se vivenciou a experiência, se se emocionou ou não, etc. O lado direito é analítico, com questões mais objetivas: descreve-se o que se viu, a sequência em que os fenômenos ocorreram, começa-se a fazer as primeiras teorizações e a relacionar o que foi vivenciado com teorias de outros/as autores/as. Portanto, no lado direito teoriza-se sobre a experiência.

O/a iniciante em Antropologia pode se questionar: "para que escrever o lado esquerdo do diário? O lado direito, evidentemente, serve como registro das informações e facilita depois na hora da escrita do texto antropológico, mas por que anotar como eu me sentia em campo?" De acordo com Miriam Grossi, a importância de se escrever o lado esquerdo, de registrar, assim, a nossa subjetividade, está no fato de que "todo conhecimento nos envolve enquanto pessoa. Ele fala de nossa vida, fala de nossa experiência"8. Além disso, conforme relatou Claudia Fonseca, escrever o diário "é poder viver o campo mais uma vez, reviver a emoção".

Em tempos tecnológicos como os atuais, o diário não precisa, necessariamente, ser um caderno; ele pode ser feito no computador. Entretanto, ainda assim é preciso separar a parte

\footnotetext{
${ }^{7}$ Importa salientar que são preferíveis os blocos de nota que possuam a capa dura, a fim de facilitar a escrita nas diversas situações que se colocam durante o campo.

${ }^{8}$ GROSSI, Miriam. Trabalho de Campo, Ética, Subjetividade e Engajamento. 2014.2. UFSC. Notas de aula. ${ }^{9}$ FONSECA, Claudia. Dueto Fronteiras da Etnografia: Hélio Silva e Claudia Fonseca. In: 29 ${ }^{\mathbf{a}}$ Reunião Brasileira de Antropologia, Natal/RN, 2014.
} 
"esquerda" e a "direita". Isso pode ser feito através de duas colunas, como se fosse, de fato, um caderno aberto, ou então o que estaria do lado esquerdo pode ser escrito em destaque (itálico, negrito, outra cor) para marcar a diferença com o texto do lado direito. ${ }^{10}$

Por fim, em relação ao diário, é fundamental salientar que existem dois elementos textuais que são centrais: tempo e espaço. O espaço é o território, é o que dá materialidade ao que está acontecendo e precisa ser descrito da maneira mais minuciosa possível; não basta escrever que algo ocorreu em uma 'sala de aula', é preciso descrever, caracterizar essa sala de aula. Por quê? Porque categorias de espaço são culturais, logo, se não estiverem bem descritas o/a leitor/a que não compartilha da mesma sociabilidade do/a autor/a poderá não compreender o que está relatado. Assim como o contexto do espaço deve estar especificado no diário de campo, o tempo também precisa ser bem descrito: qual era o dia da semana? Como estava o clima? Qual era a estação do ano? A situação relatada ocorreu de manhã ou de noite? No momento em que se faz a pesquisa esses dados podem parecer irrelevantes, entretanto, uma vez registrados poderão ser utilizados no futuro, revelando novas relações e explicações/ interpretações acerca do que se estuda.

A realização de entrevistas é outra técnica muito recorrente quando se vai a campo. E, normalmente, elas são registradas por meio de gravador ${ }^{11}$. Esse objeto tem a função de saber quais foram as palavras que o/a interlocutor/a utilizou, ou seja, grava-se para não se esquecer do que foi dito: "estamos em campo permanentemente lutando contra o esquecimento" (SILVA, 2009, p. 182). Mas o aparelho pode possuir também outra utilidade para além da questão do registro: servir para dar legitimidade ao pesquisador/a, isto é, trata-se de um instrumento que demonstra que a pessoa é de fato um/a pesquisador/a. Desse modo, o gravador é, por vezes, uma porta de entrada para conversar com os indivíduos que se estuda ou se pretende estudar. Entretanto, cabe ao investigador/a estar atento às especificidades de seu campo, posto que, ocasionalmente, ao invés de facilitar, o aparelho pode ser um impeditivo para que os/as interlocutores/as falem.

Uma questão relevante é sobre a transcrição das entrevistas. Faz-se importante realizar a transcrição completa para que as informações não se percam (é muito trabalhoso, mas se deve transcrever na íntegra, visto que os áudios podem se danificar com facilidade ou enfrentar problemas técnicos, como incompatibilidade de softwares, etc. $)^{12}$.É o/a pesquisador/a que deve

${ }^{10}$ A fim de uma discussão sobre as vantagens e desvantagens de se fazer o diário de campo no computador ver Calavia Sáez (2013, p. 165-166).

${ }^{11} \mathrm{Ou}$ por instrumentos que gravam áudio, como o caso da maior parte dos aparelhos celulares hoje em dia.

${ }^{12}$ Por ser trabalhoso o processo de transcrição, é prudente que as gravações não sejam demasiadamente longas. 
fazer as transcrições, afinal, dá mais trabalho corrigi-las - quando se paga para alguém realizar esse trabalho - do que fazê-las por si próprio/a. Além disso, é no momento que se está realizando esta atividade que as ideias sobre a pesquisa vêm à tona, que acontecem os 'insights'.

A professora Miriam Grossi, durante suas aulas, revelou-nos três dicas acerca da realização de entrevistas. A primeira é que ela costuma ir digitando em seu computador o que a pessoa está dizendo durante a entrevista, ao mesmo tempo em que a gravação é feita. Assim, basta escutar o áudio depois e preencher o que não se conseguiu digitar, facilitando, pois, o trabalho da transcrição. A segunda dica é que o/a pesquisador/a deve começar a se despedir, dizer que vai embora, cerca de trinta ou quarenta minutos antes do horário em que realmente pretende partir, porque é nesse momento - quando se começa a agradecer, insinuando que se vai embora e que a entrevista está encerrada - que os/as interlocutores/as costumam falar o que mais interessa para a pesquisa. Por fim, é interessante entrar em contato com o/a entrevistado/a um ou dois dias depois da conversa, com a intenção de saber se ele/a reavaliou alguma informação, se se lembrou de mais algum fato, etc.

Agora é preciso voltar à questão da escrita antropológica. Para Geertz (1989), o ofício do antropólogo é justamente este: escrever. É também Geertz quem propõe uma aproximação da Antropologia com a Literatura, aproximação que, para Hélio Silva, é na verdade fundante da escrita antropológica:

O texto etnográfico, que sofreu os influxos do texto acadêmico, da monografia, das teses e dissertações, papers que circulam no universo acadêmico, sofreu ainda a influência do romance, esse gênero que surge contemporâneo do próprio surgimento das grandes cidades industriais da Europa (SILVA, 2009, p. 184).

Essa dupla característica do texto antropológico - acadêmico e literário - talvez seja o que, em um primeiro momento, mais chama a atenção de quem vem de outro campo do conhecimento. Lembro-me nitidamente do meu primeiro dia de aula da graduação em Relações Internacionais, quando o professor doutor disse, entre outras coisas, a nós - 'bixos' - que depois que terminássemos a graduação, fizéssemos mestrado e doutorado, a partir daí poderíamos ter nossas próprias ideias e redigi-las em primeira pessoa do singular! Antes disso, escreve-se somente em terceira pessoa do plural, ou, ainda melhor, da maneira mais impessoal possível, sem se colocar no texto. Na Antropologia, por outro lado, escreve-se normalmente em primeira pessoa e, além disso, via de regra, valoriza-se o 'colocar-se no texto', ou seja, a evidência da subjetividade. Desse modo, este é meu primeiro texto acadêmico o qual redijo em primeira pessoa do singular e faço questão de mostrar o meu local de fala. 
Por não ser um texto acadêmico da maneira positivista convencional, há uma preocupação acerca da estética no escrever antropológico. Um exemplo sobre essa discussão é o livro "Ética e Estética na Antropologia" (LEITE, 1998). No capítulo dessa obra intitulado “Trotsky e Travesti”, Luiz Eduardo Soares reflete sobre o que é escrever bem. Para ele, o texto antropológico não deve seguir o padrão de 'pureza positivista', no qual primeiro conheceríamos e depois transmitiríamos as descobertas, mas também não pode ser transbordamento emotivo, isto é, colo maternal ou sessão de psicanálise. Para Soares, o desafio que se coloca ao antropólogo/a não é escrever bem ou mal, bonito ou feio.

O desafio é: construir nosso objeto, convertendo-o em material discursivo, de modo a revelar e comunicar os sentidos que identificamos na pesquisa, cujo movimento intelectual/hermenêutico inclui a dinâmica criativa da elaboração descritiva. Em outras palavras: a etnografia é uma tarefa da linguagem, além de ser um empreendimento de observação (LEITE, 1998, p. 69).

Por fim, faz-se preciso comentar acerca de outro ponto importante no que se refere à escrita: a questão do anonimato. Esse tema é discutido por Cláudia Fonseca em seu artigo "O anonimato e o texto antropológico" (2005). A autora começa por afirmar que havia 'naturalizado' o anonimato, acionando-o automaticamente em todos os seus textos: "até nas minhas pesquisas sobre prostitutas, eu criava nomes para substituir seus já inventados 'nomes de batalha"” (FONSECA, 2005, p. 41). A antropóloga começou a refletir sobre o assunto, entretanto, quando uma de suas orientandas se recusou a usar nomes fictícios em sua pesquisa sobre uma comunidade pleiteando direitos quilombolas. Logo depois, conta Fonseca, "um colega da área de estudos indígenas contestou um estudante que tinha mudado os nomes de seus informantes de um assentamento do MST" (FONSECA, 2005, p. 42).

Há, portanto, ocasiões em que o/a antropólogo/a pode - ou deve, de acordo com a interpretação acerca do contexto - manter os nomes reais dos/as interlocutores/as. O/a antropólogo/a iniciante, sem 'pedigree', precisa ter extrema atenção a esse tema, a fim de evitar problemas éticos. Na dúvida, o melhor é optar pelo anonimato. Conforme coloca a própria Cláudia Fonseca:

[...] não deve haver postura única frente à questão do anonimato em nossos textos. Hoje, os antropólogos estão se engajando cada vez mais em espaços extra acadêmicos onde lhes cabe estilos diversos de pesquisa e de texto escrito. [...] Entretanto, na tensão do debate, acho importante lembrar que existe determinado estilo etnográfico em que há bons motivos para manter o anonimato (FONSECA, 2005, p. 51). 


\section{Considerações finais}

O objetivo deste artigo foi trazer algumas questões relevantes acerca de trabalho de campo na Antropologia para iniciantes que, como eu, também não possuem 'pedigree'. Recorremos a diversos/as autores/as, como Bronislaw Malinowski, Ruth Benedict, Gilberto Velho, Emerson Giumbelli, entre outros/as, para contextualizar a realização do trabalho de campo, bem como problematizar se essa é a única metodologia possível na Antropologia. Também discorremos acerca da especificidade da escrita antropológica, por vezes, distante de outras formas de se escrever do mundo acadêmico.

Por fim, destaco, novamente, que a intenção ao escrever esse artigo como trabalho final para a disciplina foi compartilhar o meu local de fala atual com outros/as sujeitos/as que estejam em situação parecida: a liminaridade acadêmica de quem não vem de uma graduação em Antropologia ou Ciências Sociais, mas pretende seguir carreira nessa área do conhecimento.

\section{REFERÊNCIAS}

BENEDICT, Ruth. O crisântemo e a espada: padrões da cultura japonesa. São Paulo: Perspectiva, 1972.

CALAVIA SÁEZ, Oscar. Esse obscuro objeto de pesquisa. Um manual de método, técnicas e teses em antropologia. Ilha de Santa Catarina: Edição do Autor, 2013.

FONSECA, Claudia. O anonimato e o texto antropológico: dilemas éticos e políticos da etnografia 'em casa'. Teoria e Cultura, v. 2, n. 1, p. 39-53, 2008.

GEERTZ, Clifford. A Interpretação das Culturas. Rio de Janeiro: LTC, 1989.

GIUMBELLI, Emerson. Para além do "trabalho de campo": reflexões supostamente malinowskianas. Revista Brasileira de Ciências Sociais, v. 17, n. 48, p. 91-107, 2002.

HARAWAY, Donna. Saberes localizados: a questão da ciência para o feminismo e o privilégio da perspectiva parcial. Cadernos Pagu, n. 5, p. 07-41, 1995.

LEITE, Ilka (org.). Ética e Estética na Antropologia. Florianópolis: PPGAS/ UFSC, 1998.

MALINOWSKI, Bronislaw. Argonautas do Pacífico Ocidental. São Paulo: Abril Cultural (Coleção: Os Pensadores), 1978.

MAUSS, Marcel. Manual de Etnografia. Lisboa: Publicações Dom Quixote, 1993.

TURNER, Victor. A Floresta de Símbolos. Niterói: EDUFF, 2005. 
SILVA, Hélio R. S. A Situação Etnográfica: andar e ver. Horizontes Antropológicos, v. 15, n. 32, p. 171-188, 2009.

SOARES, Luiz E. Trotsky e Travesti. In: I. Leite (org.). Ética e Estética na Antropologia. Florianópolis: PPGAS/UFSC, 1998.

VELHO, Gilberto. Observando o familiar. In: NUNES, E.; EDSON, O. (Orgs.). A Aventura Sociológica: objetividade, paixão, improviso e método na pesquisa social. Rio de Janeiro: Zahar Editores, 1978.

\section{Como referenciar este artigo}

ANDRADE, Vítor Lopes. Trabalho de campo - Notas para iniciantes em Antropologia. Rev. Sem Aspas, Araraquara, v. 8, n. 1, p. 103-114, jan./jun., 2019. ISSN: 2358-4238. DOI: 10.29373/sas.v8i1.12748.

Submetido em: 18/05/2019

Aprovado em: 24/06/2019 